\title{
Immunostimulatory effects of cell wall-based nanoparticles in boiled Glycyrrhizae radix water extracts involves TLR4
}

\author{
HIROFUMI IITSUKA* , KEIICHI KOIZUMI*, MIKIKO SUZAKI, YOSHIKI OTSUKA, \\ MICHIKO JO and NAOTOSHI SHIBAHARA
}

Division of Kampo Diagnostics, Institute of Natural Medicine, University of Toyama, Toyama 930-0194, Japan

Received May 23, 2019; Accepted December 31, 2019

DOI: $10.3892 /$ br.2020.1294

\begin{abstract}
A number of immunostimulant effects of herbal medicines have been reported; however, the underlying mechanisms of their immunostimulatory effects have not been elucidated in detail. Our previous study showed that sugar-based nanoparticles derived from cell walls acted as the immunostimulatory component of boiled Glycyrrhizae radix water extracts. Therefore, the aim of the present study was to clarify the molecular mechanisms by which these cell wall-based nanoparticles functioned as immunostimulants. Mouse macrophage RAW-blue cells were stimulated by these nanoparticles and several immunological effects were investigated. When phosphorylation of nuclear factor- $\kappa \mathrm{B}(\mathrm{NF})-\kappa \mathrm{B}$ p65 subunit was increased, the expression of the inflammatory cytokines interleukin- 6 and tumor necrosis factor- $\alpha$ were induced via $\mathrm{NF}-\kappa \mathrm{B}$. On the other hand, Toll-like receptor 4 recognizes cell wall components of bacteria and fungi. In the present study, it was also shown that these cell wall-based nanoparticles serve an immunostimulatory role as ligands of Toll-like receptor 4 by RNA interference experiments. The results of the present study suggested that the signaling pathway of nanoparticles obtained from boiled Glycyrrhizae radix water extracts, at least partially involved TLR4 and downstream signaling from this receptor, resulting in the immunostimulatory effects of these nanoparticles in RAW-blue cells.
\end{abstract}

\section{Introduction}

The immunostimulatory effects of herbal medicines, such as Kampo in Japan and Chinese herbal medicines, have been extensively reported. Herbal medicines are prescribed for

Correspondence to: Dr Keiichi Koizumi, Division of Kampo Diagnostics, Institute of Natural Medicine, University of Toyama, 2630 Sugitani, Toyama 930-0194, Japan

E-mail: kkoizumi@inm.u-toyama.ac.jp

\section{*Contributed equally}

Key words: herbal extracts, nanoparticles, immunostimulatory effects infection and tumor, and one of their properties is strong immunostimulatory effects, including increased phagocytosis and antibody production $(1,2)$. However, limited information is currently available regarding the immunostimulant components of these herbal medicines. In our previous, it was demonstrated using electron microscopy that cell wall-based nanoparticles were universally present in boiled water herbal extracts and these nanoparticles were isolated using ultracentrifugation (3). In the present study, the immune effects of cell wall-based nanoparticles isolated from boiled Glycyrrhizae radix, the root and stolon of Glycyrrhiza uralensis Fischer (4) water extracts were primarily investigated, as this is a commonly used herb in traditional herbal medicines (5). The isolated nanoparticles are taken up by mouse macrophages (RAW-blue cells) via phagocytosis, triggering immunostimulatory effects and inducing the expression of the inflammatory cytokines, interleukin-6 (IL-6) and tumor necrosis factor- $\alpha$ (TNF- $\alpha$ ) in RAW-blue cells (3). However, the molecular mechanisms underlying these immunostimulatory effects have not yet been elucidated as these nanoparticles have only recently been discovered. Macrophages are a type of phagocytotic immune cell which primarily exert immunostimulatory effects, such as inflammatory responses (6). The inflammatory response mediated by macrophages are induced by pattern recognition receptors, such as Toll-like receptors (TLRs) $(7,8)$ and Dectin-1 $(9,10)$. RAW-blue cells are a macrophage cell line stably transfected with secreted embryonic alkaline phosphatase (SEAP) reporter gene construct which is inducible by $N F-\kappa B$ (11). Therefore, RAW-blue cells were used for monitoring the activation of $\mathrm{NF}-\kappa \mathrm{B}$, which is part of the downstream signaling pathway of TLRs and Dectin-1 $(7,8)$. The aim of the present study was to determine the signaling pathway underlying the immunostimulatory effects of nanoparticles from boiled herbal water extracts of Glycyrrhizae radix and to identify the receptors involved.

\section{Materials and methods}

Antibodies and reagents. A phospho-specific antibody against $\mathrm{NF}-\kappa \mathrm{B}$ p65 (Ser-536; cat. no. 93H1) was purchased from Cell Signaling Technology, Inc. Antibodies against $\beta$-actin (C-11; cat. no. sc-1615) and NF-кB p65 (C-20; cat. no. sc-372) were obtained from Santa Cruz Biotechnology, Inc. Secondary antibodies used were horseradish peroxidase-conjugated 
anti-rabbit (cat. no. P0448) or anti-mouse (cat. no. P0260) immunoglobulin G (Dako; Agilent Technologies, Inc.). Negative control small interfering (si)RNA and TLR4-siRNA were purchased from Santa Cruz Biotechnology. Inc. Dectin-1 siRNA was purchased from Thermo Fisher Scientific, Inc. Lipofectamine ${ }^{\circledR}$ RNAiMAX transfection reagent was obtained from Thermo Fisher Scientific, Inc. Normocin, Zeocin and Quanti-Blue were purchased from InvivoGen. Dexamethasone (Dex), an NF- $\kappa$ B inhibitor, was purchased from Wako Pure Chemical Industries, Ltd. Block Ace for western blotting was obtained from DS Pharma Medical Glycyrrhizae radix was obtained from Tochimoto Tenkaido, Co., Ltd.

Cell line and culture. RAW-blue cells were cultured in DMEM, High Glucose with L-glutamine, phenol red and sodium pyruvate (Wako Pure Chemical Industries, Ltd.) supplemented with $10 \%$ heat-inactivated FBS, $50 \mathrm{U} / \mathrm{ml}$ penicillin, $50 \mu \mathrm{g} / \mathrm{ml}$ streptomycin and $100 \mu \mathrm{g} / \mathrm{ml}$ normocin at $37^{\circ} \mathrm{C}$ in a humidified incubator with $5 \% \mathrm{CO}_{2}$.

Isolation of nanoparticles from boiled Glycyrrhizae radix water extracts. Boiled herbal water extracts were prepared by gently boiling $100 \mathrm{~g}$ Glycyrrhizae radix in $500 \mathrm{ml}$ water for $50 \mathrm{~min}$ at $95^{\circ} \mathrm{C}$ and then filtering the decoction. The decoction was centrifuged at $3,000 \mathrm{x}$ g for $5 \mathrm{~min}$ at $4^{\circ} \mathrm{C}$ (Kubota 6800; Kubota Corporation) and the supernatant was collected and then centrifuged at $20,000 \times \mathrm{g}$ for $20 \mathrm{~min}$ at $4^{\circ} \mathrm{C}$. The supernatant $(60 \mathrm{ml})$ was collected again and ultra-centrifuged at $140,000 \times \mathrm{g}$ for $50 \mathrm{~min}$ twice at $4^{\circ} \mathrm{C}$, according to a previously described method for preparation of exosomes (8). After removal of the supernatant, the transparent pellet was dispersed in distilled water $(40 \mathrm{ml})$ and freeze-dried.

Scanning electron microscopy (SEM). Negative staining was performed as follows: Collodion mesh (Nisshin EM Co., Ltd.) was placed on a $20 \mu \mathrm{l}$ droplet of nanoparticle solution $(100 \mu \mathrm{g} / \mathrm{ml})$ for $30 \mathrm{sec}$ and the solution was absorbed with filter paper. Subsequently, the mesh was placed on a droplet of $2 \%$ uranyl acetate for $5 \mathrm{sec}$, which was absorbed with filter paper, and dried. Nanoparticles which were negatively stained were observed using a JSM-6700F SEM (JEOL, Ltd.) operated using PCSEM software version 1 (JEOL, Ltd.) at a calibrated magnification of $\times 50,000$.

NF-kB-SEAP reporter assay. A total of $0,1,1.5,5$ and $10 \mu \mathrm{g} / \mathrm{ml}$ nanoparticles were added to the cell culture medium of RAW-blue cells and incubated for $20 \mathrm{~h}$, where $0 \mathrm{mg} / \mathrm{ml}$ was used as the control. The cell culture supernatant was collected and transferred to QUANTI-Blue medium (InvivoGen) and SEAP expression was then measured after $1 \mathrm{~h}$ or $90 \mathrm{~min}$ at $620 \mathrm{~nm}$ using a spectrophotometer.

Western blotting. Whole cell lysates were extracted using lysis buffer (20 mM HEPES-NaOH, 0.3 M NaCl, $1.5 \mathrm{mM} \mathrm{MgCl}$, $0.2 \mathrm{mM}$ EDTA, $0.001 \%$ Triton $\mathrm{X}-100,1 \mathrm{mM}$ DTT, $1 \mathrm{mM}$ sodium orthovanadate, $20 \mathrm{mM} \beta$-glycerophosphate disodium salt hydrate, $10 \mu \mathrm{g} / \mathrm{ml}$ aprotinin, $10 \mu \mathrm{g} / \mathrm{ml}$ leupeptin and $1 \mathrm{mM}$ PMSF). Protein concentrations in lysates were quantified using a Bradford assay, (Bio-Rad Laboratories, Inc.). The lysates were mixed with an equivalent volume of SDS sample buffer
(100 mM Tris-HCl, pH 6.8; 2.0\% SDS; 70 mM DTT; 10\% glycerol; and $0.10 \%$ bromophenol blue) and heated at $95^{\circ} \mathrm{C}$ for $5 \mathrm{~min}$. Samples were loaded onto a $9 \%$ gel, resolved using SDS-PAGE and subsequently transferred onto an Immobilon-P nylon membrane (EMD Millipore). The membrane was blocked using $4 \%$ Block Ace overnight at $4^{\circ} \mathrm{C}$, and probed with primary antibodies $(\mathrm{NF}-\kappa \mathrm{B}$ p65, rabbit anti-phospho $\mathrm{NF}-\kappa \mathrm{B}$ p65 and $\beta$-actin; all at 1:1,000), for $90 \mathrm{~min}$ at room temperature. Primary antibodies were detected using the horseradish peroxidase-conjugated anti-rabbit antibody $(1: 2,000)$ and visualized using an ECL system (GE Healthcare). The density of the blots was quantified using ImageJ version 1.8.0_172 (National Institutes of Health). Experiments were repeated at least three times and representative results are shown.

RNA interference. Mouse TLR4-siRNA (cat. no. sc-40261), mouse Dectin-1-siRNA (cat. no. sc-63277) and negative control (cat. no. sc-37007) were purchased from Santa Cruz Biotechnology, Inc. RAW-blue cells were transfected with siRNAs at a final concentration of $100 \mathrm{nM}$ using Lipofectamine ${ }^{\circledR}$ RNAiMAX transfection reagent (Thermo Fisher Scientific, Inc.) according to the manufacturer's protocol. After $12 \mathrm{~h}$, the medium was replaced with fresh medium and the cells were cultured in the presence of nanoparticles for a further $24 \mathrm{~h}$. TLR4 siRNA (cat. no. sc-40261) is a pool of 3 different siRNA duplexes. sc-40261A sense, CUAGCCUUC UUCAAUCUUAtt and antisense, UAAGAUUGAAGAAGG CUAGtt; sc-40261B sense, CCGUUGGUGUAUCUUUGA Att and antisense, UUCAAAGAUACACCAACGGtt; and sc-40261C sense, GAAGGCCCAUAUUUGACUAtt and antisense, UAGUCAAAUAUGGGCCUUCtt. Dectin-1 siRNA sequences were as follows: Dectin-1 sense, GACAACUUC CUAUCAAGAAtt and antisense, UUCUUGAUAGGAAGU UGUCtt. The sequences of the negative control siRNAs used were not disclosed by the manufacturer.

Reverse transcription-quantitative $(R T-q) P C R$. Total RNA from the RAW 264.7 cells was extracted using RNeasy Mini kit (Qiagen, Inc.) according to the manufacturer's protocol. First-strand cDNA synthesis was performed using the RNA as the template $(2 \mu \mathrm{g})$ using oligo(dT)18 primer and SuperScript III reverse transcriptase (Invitrogen; Thermo Fisher Scientific Inc.). Reverse transcription was performed at $42^{\circ} \mathrm{C}$ for $50 \mathrm{~min}$ and then at $70^{\circ} \mathrm{C}$ for $15 \mathrm{~min}$. qPCR amplification was performed using a FastStart Essential DNA Green Master mix (Roche Diagnostics). The thermocycling conditions were: Denaturation at $94^{\circ} \mathrm{C}$ for $5 \mathrm{sec}$, annealing at $60^{\circ} \mathrm{C}$ for $5 \mathrm{sec}$ and extension at $72^{\circ} \mathrm{C}$ for $10 \mathrm{sec}$ for 28 cycles qPCR was performed using a Lightcycler nano system (Roche Diagnostics) according to the manufacturer's protocol. $\beta$-actin was used as the internal control. The relative quantification of mRNA expression was calculated as a ratio of the target gene to $\beta$-actin (12). Primer sequences were as follows: TLR4 forward, 5'-GGACTCTGA TCATGGCACTG-3' and reverse, 5'-CTGATCCATGCATTG GTAGGT-3'; Dectin-1 forward, 5'-TTGTGTCGCCAAAAT GCTAGG-3' and reverse, 5'-CTGATCCATGCATTGGTA GGT-3'; IL-6 forward, 5'-GCTACCAAACTGGATATATAA TCAGGA-3' and reverse 5'-GGTCTGGGCCATAGAACT GA-3'; TNF- $\alpha$ forward 5'-TCTTCTCATTCCTGCTTGTTG-3' and reverse, 5'-GGTCTGGGCCATAGAACTGA-3'; and 


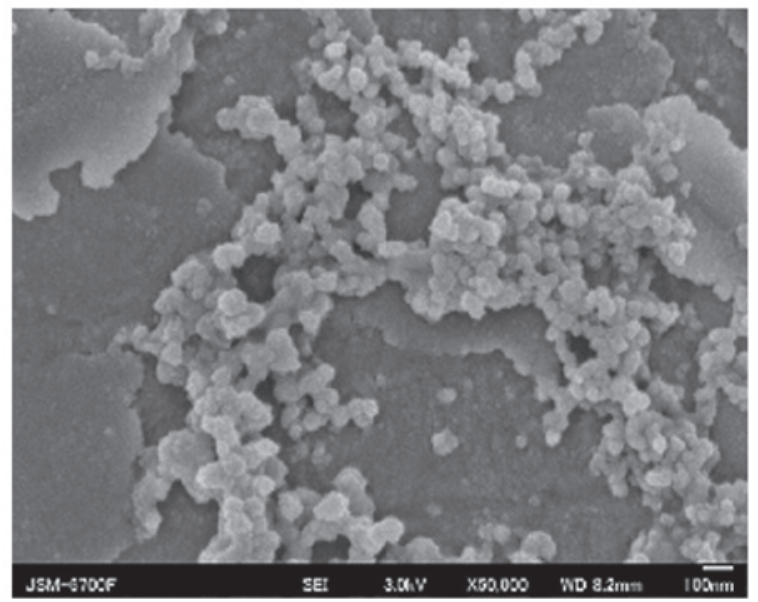

Figure 1. Scanning electron microscopy of the freeze-dried nanoparticles. Aggregates of nanoparticles from boiled Glycyrrhizae radix water extracts were observed and imaged.

$\beta$-actin forward, 5'-CTAAGGCCAACCGTGAAAAG-3' and reverse, 5'-ACCAGAGGCATACAGGGACA-3'.

Statistical analysis. Data are presented as the mean \pm standard deviation of at least 3 independent experiments. Differences between groups were compared using an ANOVA with a post-hoc Tukey-Kramer test. Statistical analyses were performed using JMP Pro software version 13 (SAS Institute). $\mathrm{P}<0.05$ was considered to indicate a statistically significance difference.

\section{Results}

SEM of nanoparticles. Freeze-dried nanoparticles from boiled Glycyrrhizae radix water extracts were visualized using SEM. The diameter of the nanoparticles were 80-100 nm (Fig. 1).

$N F-\kappa B$ activation by nanoparticles. The effects of the nanoparticles on RAW-blue cells were investigated using a reporter gene assay with $\mathrm{NF}-\kappa \mathrm{B} . \mathrm{NF}-\kappa \mathrm{B}$ activation in RAW-blue cells was significantly higher when treated with nanoparticles compared with the control, and NF- $\kappa \mathrm{B}$ activation was increased in a dose-dependent manner (Fig. 2A). This activation was suppressed by the $N F-\kappa B$ inhibitor Dex (Fig. 2B). Furthermore, nanoparticles induced the phosphorylation of the $\mathrm{NF}-\kappa \mathrm{B}$ subunit p65 (Fig. 3A and B) and this phosphorylation was suppressed by Dex in the western blotting analysis (Fig. 3C and D).

Expression levels of inflammatory cytokines are increased by nanoparticles. Based on the activation of NF- $\kappa \mathrm{B}$, cytokine production induced by nanoparticles in RAW-blue cells was examined. The mRNA expression levels of the inflammatory cytokines IL- 6 and TNF- $\alpha$, which are regulated by $N F-\kappa B$, were increased in RAW-blue cells exposed to nanoparticles compared with the control cells (Fig. 4).

Identification of receptors of nanoparticles. Based on the activation of $\mathrm{NF}-\kappa \mathrm{B}$ by nanoparticles, the receptors the nanoparticles bound to, to exert their effect in RAW-blue cells,
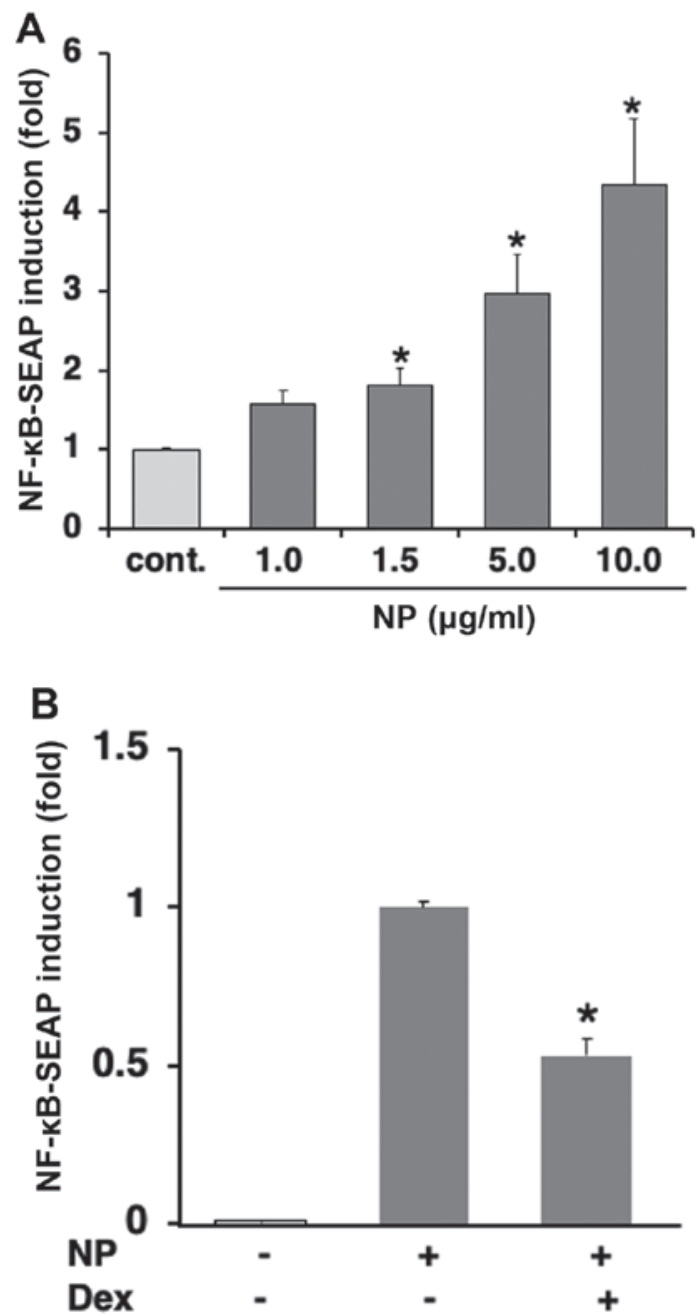

Figure 2. Nanoparticles from boiled Glycyrrhizae radix water extracts activate $N F-\kappa B$. (A) RAW-blue cells were incubated with varying concentrations of nanoparticles. NF- $\mathrm{NB}$ activation was measured by quantifying SEAP activity in the collected supernatants after incubation with Quanti-Blue reagent. ${ }^{*} \mathrm{P}<0.01$ vs. control. (B) Activation of the NF- $\kappa \mathrm{B}$ by $10 \mu \mathrm{g} / \mathrm{ml} \mathrm{NP}$ was inhibited by $1 \mu \mathrm{M}$ Dex for $1 \mathrm{~h} .{ }^{*} \mathrm{P}<0.01$ vs. control. NF- $\kappa \mathrm{B}$, nuclear factor- $\kappa \mathrm{B}$; SEAP, secreted embryonic alkaline phosphatase; Dex, dexamethasone.

were determined (Fig. 5A). Activation of NF- $\mathrm{B}$ by nanoparticles was significantly suppressed when cells were transfected with TLR4 siRNA, but not by Dectin-1 siRNA. The reduction in SEAP activity incells transfected with si-TLR4 was $\sim 50 \%$ (Fig. 5B).

Together, these results suggest that the signaling pathway by which nanoparticles obtained from boiled Glycyrrhizae radix water extracts at least partially involved TLR4, and signal transmission induced the expression of the inflammatory cytokines IL- 6 and TNF- $\alpha$ in RAW-blue cells.

\section{Discussion}

The immunostimulatory effects of herbal medicines are widely known $(1,2)$. In our previous study, it was demonstrated that juzentaihoto, a Japanese herbal medicine, increased and prolonged antibody production following an influenza vaccination in a human clinical experiment (13). However, the immunostimulatory components of herbal medicines and the underlying molecular mechanisms remain unclear. On the 
A

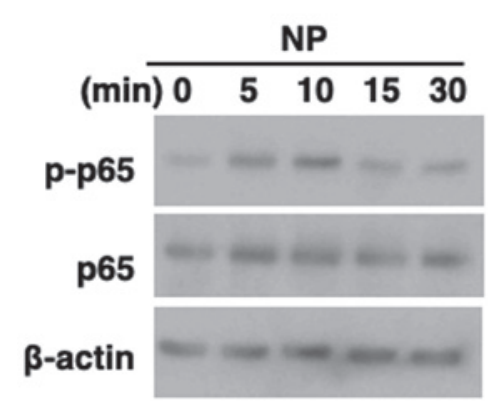

C

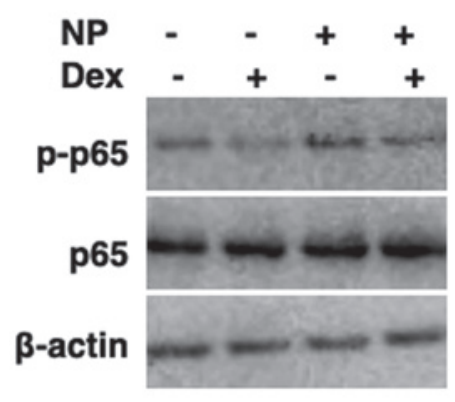

B

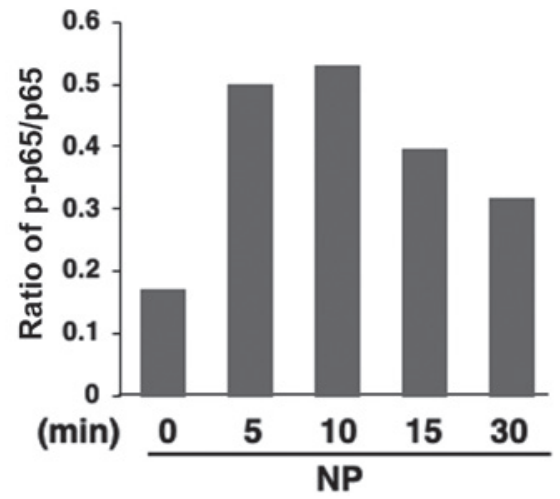

D

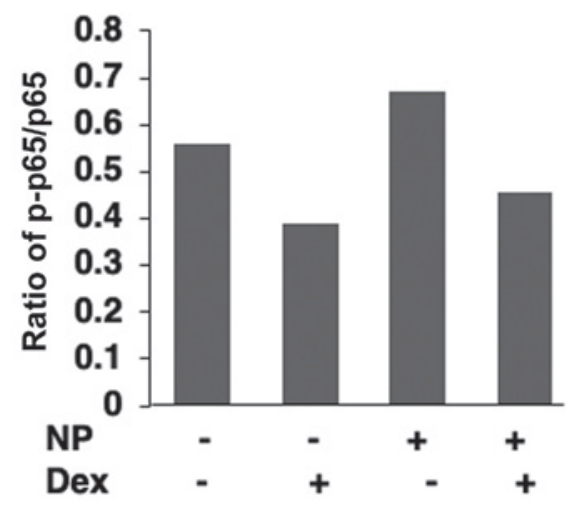

Figure 3. Nanoparticles from boiled Glycyrrhizae radix water extracts increase phosphorylation of the nuclear factor- $\mathrm{B}$ subunit $\mathrm{p} 65$. $\beta$-actin was used as a loading control. (A) RAW-blue cells were treated with $10 \mu \mathrm{g} / \mathrm{ml} \mathrm{NP}$ for $0-30 \mathrm{~min}$. (B) Ratio of p-p65/p65 protein levels were estimated by densitometry analysis. (C) Following pretreatment with $1 \mu \mathrm{M}$ Dex for $1 \mathrm{~h}$, RAW-blue cells were treated with $10 \mu \mathrm{g} / \mathrm{ml} \mathrm{NP}$ for $10 \mathrm{~min}$. (D) Ratio of p-p65/p65 protein levels were estimated using densitometry analysis. NP, nanoparticle; p-, phospho; Dex, dexamethasone.

other hand, studies investigating the sugar chains in herbal medicines have previously been performed $(14,15)$. In future studies, similarities between these reported sugar chains and these nanoparticles should be examined.

TLRs and dectin-1 are pattern-recognition receptors, which exogenous ligands [pathogen-associated molecular patterns (PAMPs)] and endogenous ligands (damage-associated molecular patterns) and subsequently induce an immune response (16).

Dectin- 1 is a $\beta$-glucan receptor and $\beta$-glucans are polysaccharide triplet chains composed of D-glucose units via $\beta-1,3$ glycosidic bonds (17). In the present study, the nanoparticles were not recognized by Dectin-1, even though the primary constituent of these nanoparticles is glucose (3). A possible explanation for this may be that the polymerized glucose constituents of the nanoparticles may not be recognized as a polysaccharide triplet chain equipped with $\beta-1,3$ glycosidic bonds by Dectin-1.

Nanoparticles obtained from boiled Glycyrrhizae radix water extracts induced $N F-\kappa B$ activation via the TLR4 signaling pathway. These results suggest that the activation of $\mathrm{NF}-\kappa \mathrm{B}$ in RAW-blue cells by nanoparticles is partially mediated by TLR4. TLR4, a TLR, and its ligand axis has been reported to activate several transcription factors, such as $\mathrm{NF}-\kappa \mathrm{B}$, in order to induce immune responses (18).

In our previous study, it was demonstrated that nanoparticles obtained from boiled Glycyrrhizae radix water extracts where composed of the cell wall components arabinogalactan and cellulose, suggesting that they are a semi-artificial assembled form of plant cell wall degradants (3). The typical TLR4 ligands of PAMPs are cell wall components of bacteria (lipopolysaccharide) and fungi (mannan), which may provide insight into the immunological function of nanoparticles as TLR4 ligands $(18,19)$. In the present study, nanoparticles from boiled Glycyrrhizae radix water extracts induced the phosphorylation of the NF- $\kappa \mathrm{B}$ subunit $\mathrm{p} 65$. It is hypothesized that the nanoparticles function as TLR4 ligands, initiating signal transduction and increasing the expression of the inflammatory cytokines TNF- $\alpha$ and IL- 6 via NF- $\kappa$ B.

TNF- $\alpha$ is an immunostimulatory cytokine that prevents infection by bacteria and viruses and eliminates tumor cells (20). IL-6 is an immunostimulatory cytokine that serves an essential role in acquired immunity through its regulation of antibody production $(21,22)$. As previously discussed, limited information is currently available concerning the immunostimulant components of herbal medicines. The present study suggests that nanoparticles from boiled Glycyrrhizae radix water extracts are novel immunostimulant components via TLR4.

The TLR4-mediated signaling pathway is regarded as an attractive pharmaceutical target, particularly for cancer therapy (23). TLR4 ligands have advanced through pre-clinical and clinical stages and two agents, Bacillus Calmette-Guérin (BCG) and monophosphoryl lipid A, have been approved for immunotherapy of in situ bladder carcinoma by the Food and Drug Administration (24). 
A

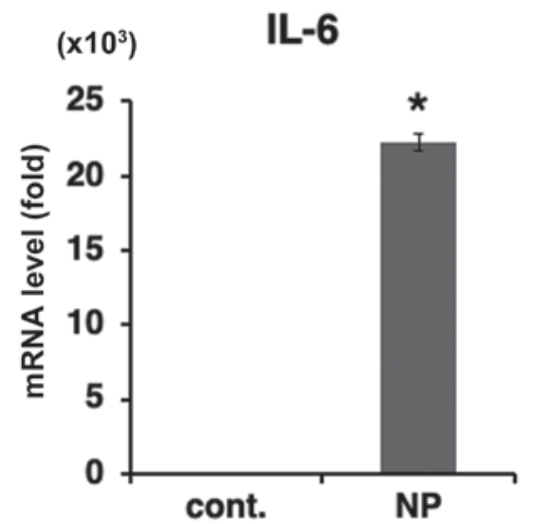

B

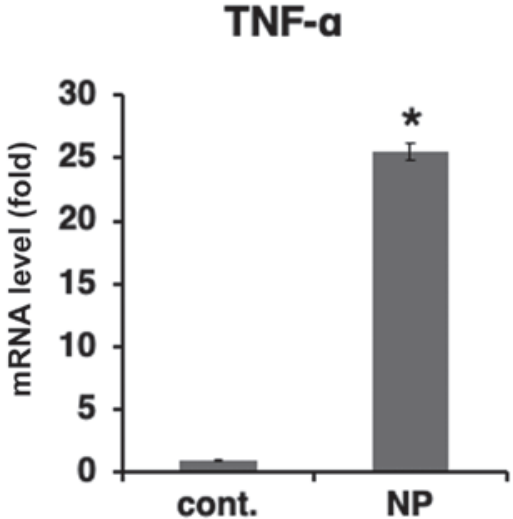

Figure 4. Nanoparticles from boiled Glycyrrhizae radix water extracts increase the expression of IL-6 and TNF- $\alpha$ inflammatory cytokine genes. RAW-blue cells were treated with $10 \mu \mathrm{g} / \mathrm{ml}$ of NP for $9 \mathrm{~h}$. mRNA expression levels of (A) IL-6 and (B) TNF- $\alpha$ were assessed using reverse transcription quantitative-PCR. ${ }^{*} \mathrm{P}<0.01$ vs. control. IL-6, interleukin-6; TNF- $\alpha$, tumor necrosis factor- $\alpha$.

A

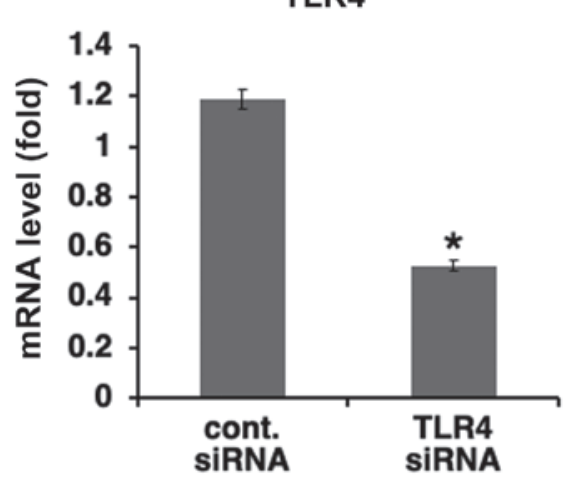

B

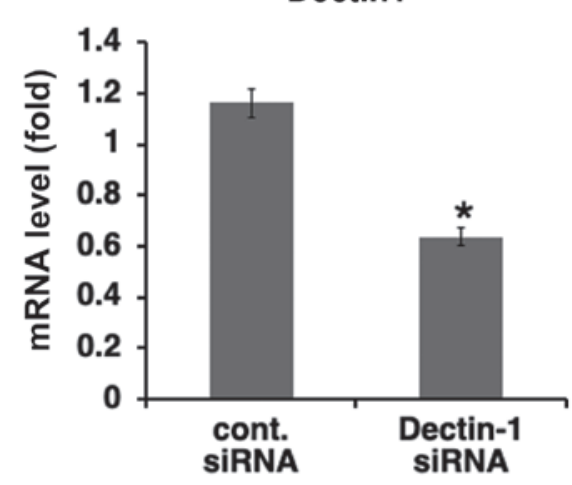

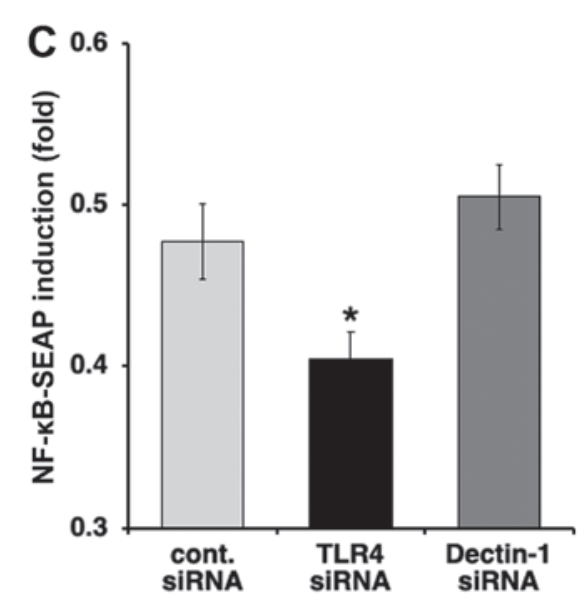

Figure 5. Silencing, TLR4 but not Dectin-1, affects NF- $\mathrm{B}$ activation mediated by nanoparticles from boiled Glycyrrhizae radix water extracts. (A) TLR4 and (B) Dectin-1 mRNA expression in RAW-blue cells measured using reverse transcription quantitative-PCR. (C) Following transfection pf si-TLR4 or si-Dectin-1 into RAW-blue cells, (C) NF- $\mathrm{B}$ activation was examined by quantifying SEAP activity. "P<0.01 vs. respective control siRNA. TLR4, Toll-like receptor 4; NF- $\kappa \mathrm{B}$, nuclear factor- $\kappa \mathrm{B}$; SEAP, secreted embryonic alkaline phosphatase; si, small interfering.

In the present study, in vivo experiments were not performed. Therefore, in future studies, the anti-cancer effects of nanoparticles from boiled Glycyrrhizae radix water extracts will need to be investigated using animal models to confirm their efficacy.

In conclusion, nanoparticles obtained from boiled Glycyrrhizae radix water extracts were demonstrated to activate the NF- $\kappa \mathrm{B}$ signaling pathway and increase the expression of inflammatory cytokines via TLR4.

BCG, which is a TLR4 agonist and a classical immunostimulants prepared from Mycobacterium tuberculosis, is an efficient type of immunotherapy used to treat patients with bladder carcinoma for $>40$ years (25). Given that nanoparticles obtained from boiled Glycyrrhizae radix water extracts are a 
TLR4 agonist prepared from a plant, the results of the present study may aid in the development of novel anti-cancer drugs such as BCG.

\section{Acknowledgements}

We would like to thank the Daicel Corporation (Osaka, Japan) and ROHTO Pharmaceutical Co., Ltd. (Osaka, Japan) for their technical support.

\section{Funding}

The present study was supported by a Grant-in-Aid for the Cooperative Research Project from the Institute of Natural Medicine, University of Toyama, Toyama, Japan (grant nos. 2014Y and 2015Y).

\section{Availability of data and materials}

The datasets used and/or analyzed during the present study are available from the corresponding author on reasonable request.

\section{Authors' contributions}

HI, KK and NS designed the research. HI, KK, MS, YO and MJ performed the experiments and prepared all the figures. HI, KK and NS wrote the paper. All authors discussed and agreed on the results, read and approved the final manuscript.

\section{Ethics approval and consent to participate}

Not applicable.

\section{Patient consent for publication}

Not applicable.

\section{Competing interests}

The authors declare that they have no competing interests.

\section{References}

1. Liu H, Wang J, Sekiyama A and Tabira T: Juzen-taiho-to, an herbal medicine, activates and enhances phagocytosis in microglia/macrophages. Tohoku J Exp Med 215: 43-54, 2008.

2. Munakata K, Takashima K, Nishiyama M, Asano N, Mase A, Hioki K, Ohnishi Y, Yamamoto M and Watanabe K: Microarray analysis on germfree mice elucidates the primary target of a traditional Japanese medicine juzentaihoto: Acceleration of IFN- $\alpha$ response via affecting the ISGF3-IRF7 signaling cascade. BMC Genomics 13: 30, 2012

3. Iitsuka H, Koizumi K, Inujima A, Suzaki M, Mizuno Y, Takeshita Y, Eto T, Otsuka Y, Shimada R, Liu M, et al: Discovery of a sugar-based nanoparticle universally existing in boiling herbal water extracts and their immunostimulant effect. Biochem Biophys Rep 16: 62-68, 2018.

4. Guo ZZ, Wu YL, Wang RF, Wang WQ, Liu Y, Zhang XQ, Gao SR, Zhang Y and Wei SL: Distribution patterns of the contents of five active components in taproot and stolon of Glycyrrhiza uralensis. Biol Pharm Bull 37: 1253-1258, 2014.

5. Nose M, Tada M, Kojima R, Nagata K, Hisaka S, Masada S, Homma Mand Hakamatsuka T: Comparison of glycyrrhizin content in 25 major kinds of Kampo extracts containing Glycyrrhizae Radix used clinically in Japan. J Nat Prod 71: 711-722, 2017.
6. Doster RS, Rogers LM, Gaddy JA and Aronoff DM: Macrophage extracellular traps: A scoping review. J Innate Immun 10: 3-13, 2018.

7. Ozinsky A, Underhill DM, Fontenot JD, Hajjar AM, Smith KD, Wilson CB, Schroeder L and Aderem A: The repertoire for pattern recognition of pathogens by the innate immune system is defined by cooperation between toll-like receptors. Proc Natl Acad Sci USA 97: 13766-13771, 2000.

8. Takeda K, Kaisho T and Akira S: Toll-like receptors. Annu Rev Immunol 21: 335-376, 2003.

9. Borriello F, Zanoni I and Granucci F: Cellular and molecular mechanisms of antifungal innate immunity at epithelial barriers: The role of C-type lectin receptors. Eur J Immunol 50: 317-325, 2020.

10. Fesel PH and Zuccaro A. $\beta$-glucan: Crucial component of the fungal cell wall and elusive MAMP in plants. Fungal Genet Biol 90: 53-60, 2016.

11. Hansen FC, Kalle-Brune M, van der Plas MJ, Strömdahl AC, Malmsten M, Mörgelin $M$ and Schmidtchen A: The thrombin-derived host defense peptide GKY25 inhibits endotoxin-induced responses through interactions with lipopolysaccharide and macrophages/monocytes. J Immunol 194: 5397-5406, 2015

12. Livak KJ and Schmittgen TD: Analysis of relative gene expression data using real-time quantitative PCR and the 2(-Delta Delta C(T)) method. Methods 25: 402-408, 2001.

13. Saiki I, Koizumi K, Goto H, Inujima A, Namiki T, Raimura M, Kogure T, Tatsumi T, Inoue H, Sakai S, et al: The long-term effects of a kampo medicine, juzentaihoto, on maintenance of antibody titer in elderly people after influenza vaccination. Evid Based Complement Alternat Med 2013: 568074, 2013.

14. Kiyohara H, Uchida T, Takakiwa M, Matsuzaki T, Hada N, Takeda T, Shibata T and Yamada H: Different contributions of side-chains in beta-D-(1->3,6)-galactans on intestinal Peyer's patch-immunomodulation by polysaccharides from Astragalus mongholics Bunge. Phytochemistry 71: 280-293, 2010.

15. Kiyohara H, Matsuzaki T and Yamada H: Intestinal Peyer's patch-immunomodulating glucomannans from rhizomes of Anemarrhena asphodeloides Bunge. Phytochemistry 96: 337-346, 2013.

16. Martínez A, Bono C, Megías J, Yáñez A, Gozalbo D and Gil ML: PRR signaling during in vitro macrophage differentiation from progenitors modulates their subsequent response to inflammatory stimuli. Eur Cytokine Netw 28: 102-110, 2017.

17. Nakashima A, Yamada K, Iwata O, Sugimoto R, Atsuji K, Ogawa T, Ishibashi-Ohgo $\mathrm{N}$ and Suzuki K: $\beta$-Glucan in foods and its physiological functions. J Nutr Sci Vitaminol (Tokyo) 64: 8-17, 2018.

18. Takeda K, Kaisho T and Akira S: Toll-like receptors. Annu Rev Immunol 21: 335-376, 2003.

19. Akira S, Uematsu S and Takeuchi O: Pathogen recognition and innate immunity. Cell 124: 783-801, 2006.

20. Casale TB and Carolan EJ: Cytokine-induced sequential migration of neutrophils through endothelium and epithelium. Inflamm Res 48: 22-27, 1999.

21. Dienz O and Rincon M: The effects of IL-6 on CD4 T cell responses. Clin Immunol 130: 27-33, 2009.

22. Hunter CA and Jones SA: IL-6 as a keystone cytokine in health and disease. Nat Immunol 16: 448-457, 2015.

23. Roy A, Srivastava M, Saqib U, Liu D, Faisal SM, Sugathan S, Bishnoi S and Baig MS: Potential therapeutic targets for inflammation in toll-like receptor 4 (TLR4)-mediated signaling pathways. Int Immunopharmacol 40: 79-89, 2016.

24. Vacchelli E, Eggermont A, Sautès-Fridman C, Galon J, Zitvogel L, Kroemer G and Galluzzi L. Trial Watch: Toll-like receptor agonists for cancer therapy. Oncoimmunology 2: e25238, 2013

25. Camargo JA, Passos GR, Ferrari KL, Billis A, Saad MJA and Reis LO: Intravesical immunomodulatory imiquimod enhances bacillus Calmette-Guérin downregulation of nonmuscle-invasive bladder cancer. Clin Genitourin Cancer 16: e587-e593, 2018.

This work is licensed under a Creative Commons Attribution-NonCommercial-NoDerivatives 4.0 International (CC BY-NC-ND 4.0) License. 